\title{
Hill climbing hysteresis of perovskite-based solar cell: a maximum power point tracking investigation
}

Norman Pellet ${ }^{1,2}$, Fabrizio Giordano ${ }^{1}$, Mohammad Ibrahim Dar ${ }^{1}$, Giuliano Gregori ${ }^{2}$,

Shaik Mohammed Zakeeruddin ${ }^{1}$, Joachim Maier ${ }^{2}$, Michael Grätzel*1,1,2

1-Laboratory for Photonics and Interfaces, Ecole Polytechnique Fédérale de

Lausanne,1015 Lausanne, Switzerland

2- Max Planck Institute for Solid State Research, Heisenbergstraße 1,70569 Stuttgart, Germany

*corresponding author : michael.graetzel@epfl.ch 
The surge of the power conversion efficiency of metal halide lead perovskite comes with concerns such as the long-term ecotoxicity of lead compounds, the sensitivity of these materials towards moisture and oxygen or the scarcity and high price of some elements, such as tin (used in the transparent conductive oxide coating the glass substrate) and gold. Among these issues, the stability of the device under real working conditions and the presence of anomalous hysteresis in the $\mathrm{J}-\mathrm{V}$ curve are perhaps the most concerning ones and, in the long run, will certainly decide on the fate of $\mathrm{CH}_{3} \mathrm{NH}_{3} \mathrm{PbI}_{3}$ and related lead perovskites for photovoltaics. Herein for the first time we analyze the power extraction from solar cells exhibiting hysteresis. We show that the standard Perturb and Observe algorithms fail to converge to the maximum power point of the solar cell when they exhibit $\mathrm{j}(\mathrm{V})$ hysteresis. An advanced new algorithm to regulate oscillations is presented and investigated. The correlation between the hysteresis behavior in the $J(V)$ curves and the time constant of the solar cells is unraveled by impedance spectroscopy. we show that enforcing oscillation in forward bias can boost the averaged power output of some perovskite solar cells, in contrast to crystalline silicon cells. Finally, we provide an effective and cheap strategy to perform maximum power point tracking of perovskite solar cells to probe their stability.

Stability concerns of $3^{\text {rd }}$ generation photovoltaics, such as dye sensitizied solar cells (DSSCs)[1], organic photovoltaics or polymer photovoltaics have long been recognized, studied and extensively reported[2-7]. Yet, when it comes to organic-inorganic perovskite-based systems, stability studies have thus far been largely overshadowed by the rapidly growing power conversion efficiencies (PCE)[8], even though some more recent studies have highlighted its importance and shown stability analysis[9,10]. We believe that it is urgent to pay greater attention to tackling stability issues together with increasing PCEs, rather than looking at the two issues separately. Performing ageing measurements on lab-scale systems can be cumbersome, especially for perovskite devices which, in most cases, show anomalous hysteresis in their $\mathrm{j}-\mathrm{V}$ characteristics[11,12]. In the case of DSSCs for example, stability would be assessed by leaving devices at open-circuit, short-circuit or under load (most often using a Schottky or Zener diode to drop a fixed potential, or with a fixed load resistance) and taken out of a solar simulator for $\mathrm{j}-\mathrm{V}$ curve measurement. Alternatively, devices can be connected to a potentiostat simulating the load by applying a fixed potential close to the Maximum power point voltage. This approach works relatively well for short-term, small-scale assessment of the cell power output to show hysteresis-free power output of the device. It is however not suited for long term, largescale studies on multiple laboratory devices and most importantly does not mimic the real situation.

Herein, we investigate the methodologies to extract photogenerated power from Perovskite solar cells even in presence of strong hysteresis. In order to do that, we have designed a small and inexpensive maximum power point tracker in the form of an electronic board that can handle up to 8 lab-scale devices simultaneously. We show that the standard perturb and observe (P\&O) algorithm fails to track the optimal power of perovskite-based cells because the hysteresis not only applies when measuring the cell from $\mathrm{V}_{\mathrm{oc}}$ to $\mathrm{J}_{\mathrm{sc}}$, but also appears in small perturbation around the maximum power point, which leads to strong oscillations of the power output. We introduce two new parameters that are required to 
stabilize the algorithm: the power-inverting threshold, which describes how much the power has to drop relatively to a previous local maxima before the $\mathrm{P} \& \mathrm{O}$ switches direction and acts as a digital hysteretic controller. Judicious choices of the algorithm parameters help reducing the oscillations and stabilize device power output. Strikingly, we found that for some devices, the best performing algorithm (with respect to the averaged power output) was not obtained when minimizing the oscillations close to the maximum power point and we attribute this peculiarity to a sort of pooling effect introduced from the tracking.

\section{Maximum power point tracking}

The power-voltage characteristics of photovoltaic cells being non-linear and heavily affected by illumination, temperature or ageing, maximum power point tracking (MPPT) control is essential in large-scale photovoltaic arrays to load them at the peak power point. Variations of sun intensity, temperature throughout the day are affected by the illumination angle, solar spectrum or partial shading (clouds, dust, ...) and can significantly shift the optimal working voltage of the solar cell. On a laboratory scale, MPPT is used to confirm the sustained power output of the cell or to perform ageing under simulated outdoor conditions. Perturb and Observe (P\&O)[13-23] and Incremental Conductance (IncCon)[14,24-29] are the most popular MPPT methods owing to their effectiveness and ease of implementation. $\mathrm{P} \& \mathrm{O}$ relies on hill climbing, where the power output is maximized by constantly perturbing voluntarily the operating voltage, unlike steady state methods such as fractional voltage or fractional current where a constant voltage or current is applied to the solar array and is based on the knowledge of the $\mathrm{j}-\mathrm{V}$ characteristics of the PV array. In P\&O, the power of the array is sampled and compared to the previous value[30]. The duty cycle of the buck-boost converter $\left(\mathrm{t}_{\mathrm{on}} / \mathrm{t}_{\text {tot }}\right.$ of the gated switch) is adapted according to whether the power increases or decreases. In IncCond, the differential conductance $(\mathrm{dI} / \mathrm{dV})$ and steady-state conductance $(\mathrm{I} / \mathrm{V})$ are determined and a tracking decision on the duty cycle of the buck-boost converter is taken accordingly[25]. Other closed loop algorithms exist, such as fuzzy logic (relies on fuzzification, table lookup and defuzzification of numerical, arbitrarily defined variables)[31-35], neural networks (relies on the learning of a parameter set)[36-38], and others, such as RCC (Ripple Correlation Current)[39], which uses the ripple current during the switching cycle of the DC-DC converter to determine the differential conductance, or load maximization[40,41]. Most of the work on MPPT algorithms aim at improving the steady-state performance, the transient response[18,42,43], and the cost of implementation[44]. However these optimizations are often valid when the PV array is connected to a buck converter[43] and usually requires prior knowledge, such as the PV characteristics of the array. Peak-current control[21] samples the voltage and current of the array upon switching times of the DC-DC converter, and can be used to improve the transient response of the tracker. This technique has gained significant traction because of its effectiveness in steady-state and transient response[39,45], but will fail if the conductance has an imaginary component at the switching frequency due low RC frequency responses, in systems such as DSCCs or PSCs. For a photovoltaic technology, these aspects are of extreme importance however, to the best of our knowledge, these power extraction methodologies have never been studied with devices showing hysteresis such in the case of Perovskite solar cells. 
The current hysteresis in the voltage sweep of organic-inorganic perovskite-based cells is well recognized, but its origin is still under debate[11,12,46]. It shows in the complex response of the impedance of the solar cell at frequencies matching the slew rate of the algorithm $(\Delta V / \Delta t)[47]$. For example, at a slew rate of $60 \mathrm{mV} \mathrm{s}^{-1}$ with a $30 \mathrm{mV}$ peak-to-peak voltage, the complex impedance of the solar cell at $1 \mathrm{~Hz}$ will induce hysteresis. Low pass filters (analog or digital) with cut-off frequencies well below $1 \mathrm{~Hz}$ would be needed to stabilize the hysteresis of the solar cell, which will result in very poor transient response. If the impedance spectrum exhibits a phase of $0^{\circ}$ at the sampling frequency, the $j(V)$ function is bijective, and the algorithm can perform with very little oscillation. Figure 1 shows the correspondence between the Nyquist impedance spectra of a $\mathrm{CH}(\mathrm{NH} 2)_{2} \mathrm{PbBr}_{3}\left(\mathrm{FAPbBr}_{3}\right)$ device acquired at a $950 \mathrm{mV}$ DC bias with a $22 \mathrm{mV}$ AC perturbation (RMS, root mean squared) under an equivalent 1 sun illumination and the Lissajous cuves (current vs voltage) recorded under the same conditions (22mV RMS perturbation, $950 \mathrm{mV}$ DC offset). When the phase is minimum, less hysteresis is observed, which occurs either at very high frequencies (above $150 \mathrm{kHz}$ ) or at intermediate frequencies $(100 \mathrm{~Hz}$ to about $2 \mathrm{kHz})$. This sets a window inside of which the MPPT algorithm should work. However, when the algorithm works below $10 \mathrm{~Hz}$, perovskite devices usually show notable imaginary frequency response down to very low frequencies. In such situations, the algorithm needs to deal with a non-symmetrical $\mathrm{j}-\mathrm{V}$ relationship

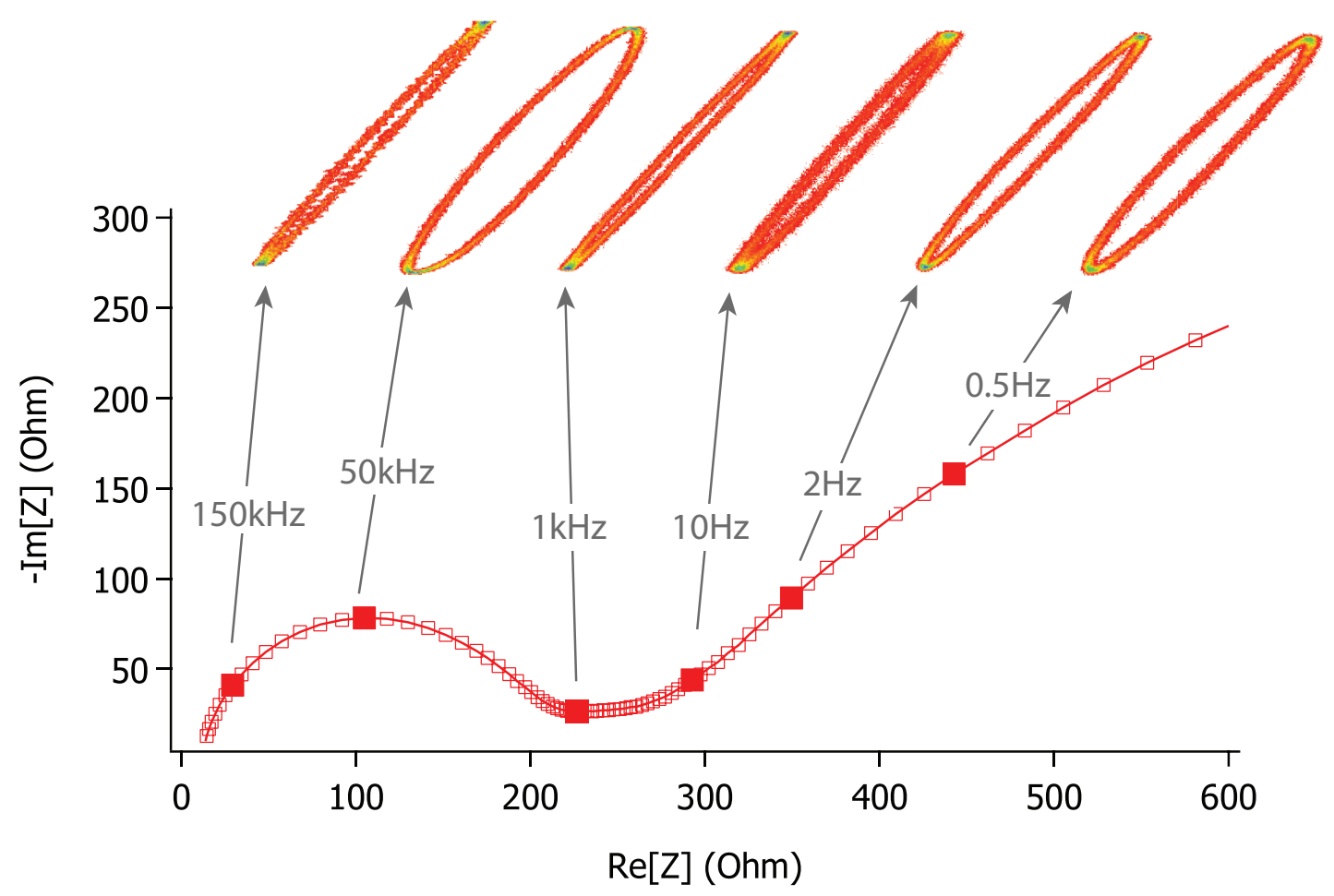

Figure 1: Nyquist impedance spectra of a $\mathrm{CH}_{3} \mathrm{NH}_{3} \mathrm{PbI}_{3}$-based mesoscopic solar cell, measured at $950 \mathrm{mV}$ under an equivalent 1 sun illumination. The Lissajous curves (current vs. voltage) corresponding to a sinusoidal perturbation $\left(V_{\text {rms }}=22 \mathrm{mV}\right)$ under the same measuring conditions (light and DC bias) are shown above for the indicated frequencies. 
Although research is being undertaken to limit or suppress the hysteresis of perovskite devices, reports of hysteresis-free solar cells mostly rely on the slow scanning of the $\mathrm{j}-\mathrm{V}$ curve, redhibitory in outdoor measurements where charges in irradiance can rapidly occur. If the hysteresis cannot be avoided, the MPPT algorithms must be adapted consequently. Hence, the $\mathrm{dP} / \mathrm{dV}=0$ criteria that describes the effective maximum power output is dependent on tracking conditions (speed, amplitude, direction) and is ill defined. A more accurate representation of the steady-state maximum power point is described by equation 1.

$$
\frac{\int_{t}^{t=\infty} V(t) I(t) d t}{\int_{t}^{t=\infty} V(t) d t}=0
$$


A

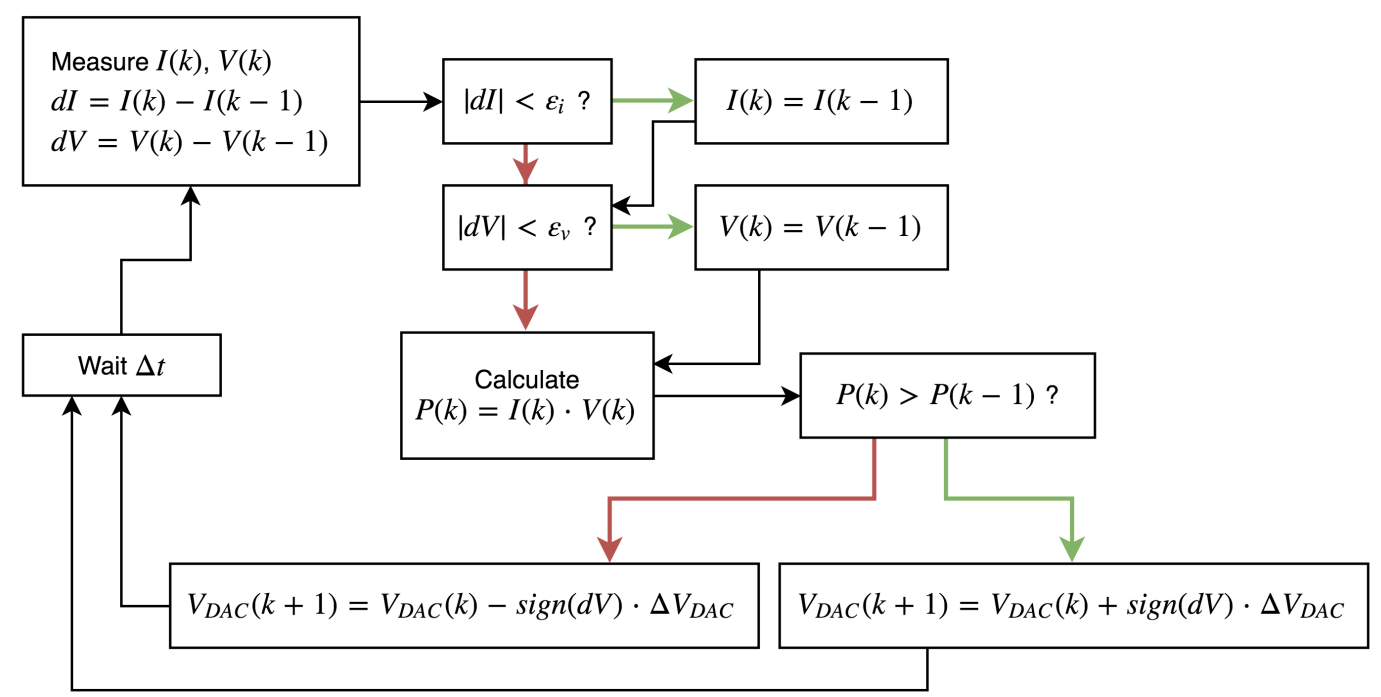

B

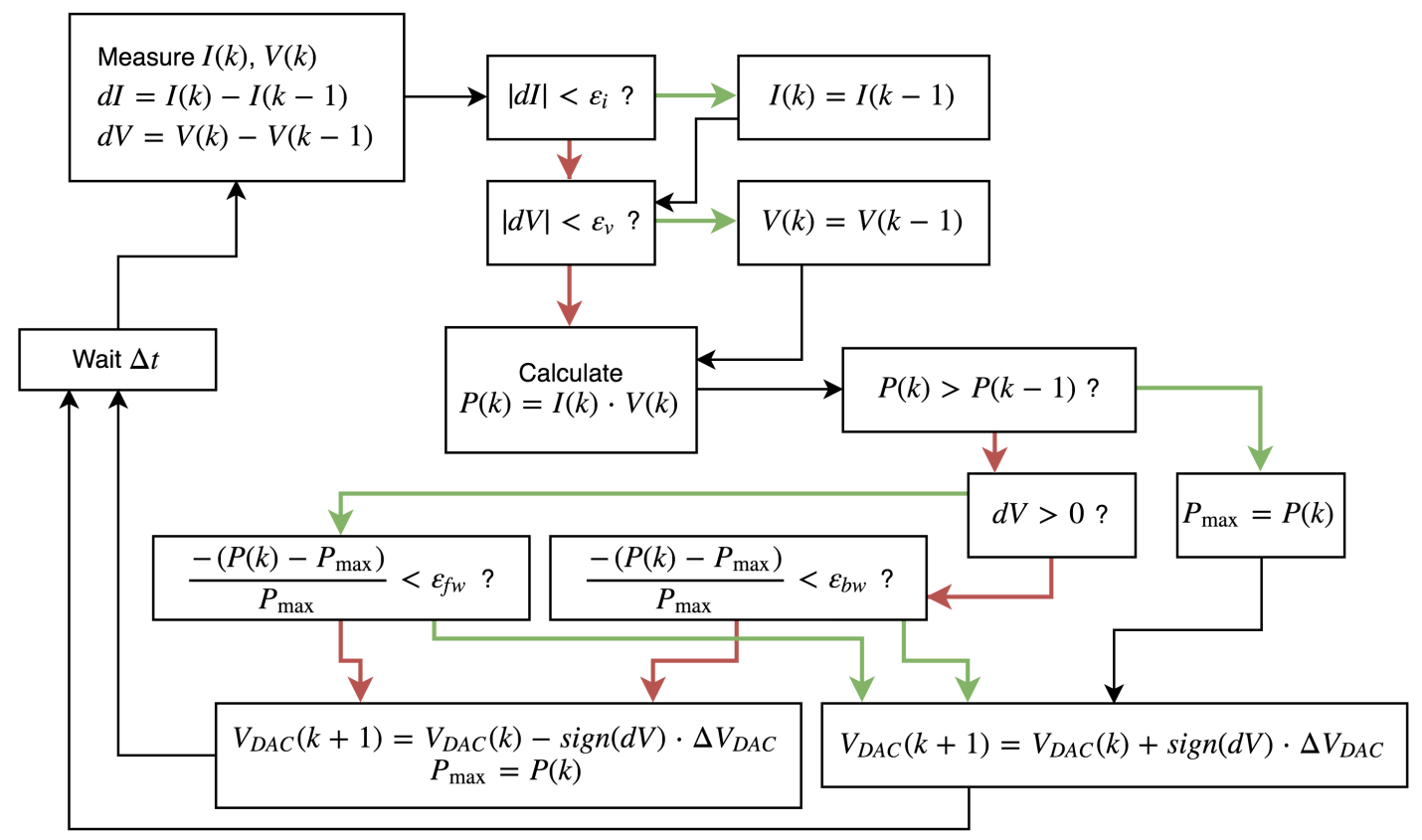

Figure 2: (a) standard perturb-and-observe (P\&O) algorithm flowchart for the generic cycle $k$, including noise thresholds $\left(\varepsilon_{i}\right.$ and $\left.\varepsilon_{v}\right)$ to correct the transient behavior of the sampler, nonlinearity and noise. In this configuration, the correction of the load is not done through adapting the duty cycle of the buck converter, but through changing the applied voltage driving the solar cell. (b) modified perturb and observe (P\&O) algorithm flowchart, including the power thresholds $\varepsilon_{\text {backward }}$ and $\varepsilon_{\text {forward }}$. The local maximum power is adapted each time the power increases or when a switch in scanning direction is done. Green arrows are followed when the condition is "true" and the red ones when it is "false".

Perturb and Observe algorithm 
Briefly, the perturb-and-observe algorithm is implemented by continuously sampling the current and the voltage of the solar cell. The power is computed and compared to the previously recorded one. If the sign of $\mathrm{dP} / \mathrm{dV}$ is positive, then the voltage is increased. If it is negative, then the voltage is decreased. Around the maximum point, the algorithm will naturally perform small oscillations, which will depend on the photovoltaic noise, light stability and resolution of the power tracker. A flowchart of the algorithm is shown in Figure 2a. The algorithm reads as follows: firstly, the current and voltage of the solar cell are sampled at the cycle $\mathrm{k}$, yielding $I(k)$ and $V(k)$. The algorithm will reject any nonsignificant voltage or current variation $(I(k)-I(k-1)$ and $V(k)-V(k-1))$, for example if variations are below the typical system noise. If any of the two variations is under their respectively defined noise thresholds, $\varepsilon_{v}$ and $\varepsilon_{I}$, their value is set to the previous one[48]. The power is then computed $(P(k))$ and compared to the previous one $(P(k-1))$. If it has increased, the voltage is incremented by the value $\operatorname{sign}(d V) \cdot \Delta V_{D A C}$ (i.e. the device is biased further into the direction it is currently going). The next step is the hill-climbing part of the algorithm. If the power output decreases compared to the previous one, the bias is incremented by $-\operatorname{sign}(d V) \cdot \Delta V_{D A C}$ (i.e. the direction of tracking is reversed), where $\Delta V_{D A C}$ is the algorithm voltage step size. In practice however, we found that this somewhat naive implementation yields poor results for the tracking of perovskite solar cells. In these devices in fact, once the algorithm has decided to switch direction based on the results of the hill-climbing part of the algorithm, the hysteretic behavior of the solar cell produces a loss of power at the step $(P(k))$ compared to the previous one $(P(k-1))$. This is in contrast to the expected increase that would be observed for a fast-responding, hysteresis-free solar cell. In a hysteretic solar cell, multiple maximum power points coexist depending on the scan rate, scan direction, voltage bias and likely, on its history. Switching the scanning direction is one of the reasons why the solar cell has more than one maximum power point. In organic-inorganic perovskite solar cells, it appears that after switching the direction from backward to forward scan, the transient maximum power point is located left from switching voltage. This leads to an apparent drop of power and confuses the algorithm, led to believe that the maximum power point is at lower voltage. The algorithm switches back the scanning direction to backward, which translates into a temporary increase of power over few millivolts, followed by a decrease, after which the algorithm switches again to forward scanning, and a similar cycle is repeated again at a lower voltage. In total, this tracking failure can span over more than $300 \mathrm{mV}$ below the first maximum power point. Overall, the tracking is done at a potential lower than optimal and the device undergoes significant voltage oscillations. The magnitude of this effect is expected to strongly depend on the voltage step size ( $2 \mathrm{mV}$ in our case) and the time delay between the DAC setting and the AD sampling. 


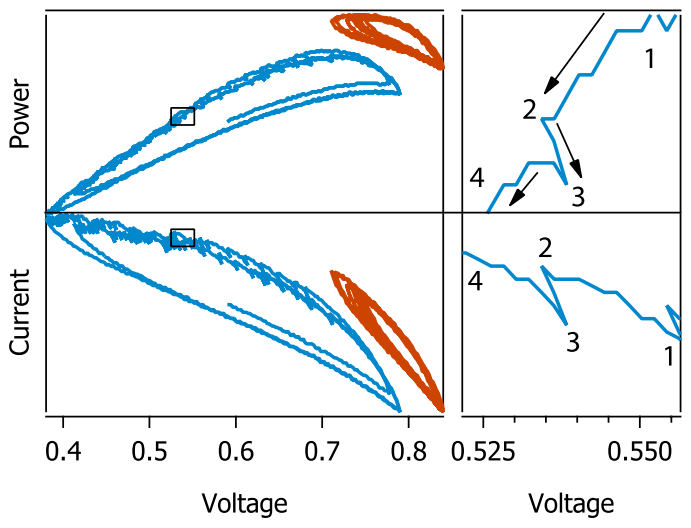

Figure 3: blue: P\&O algorithm performed without threshold regulation. The device undergoes significant oscillation. Below the maximum power point (point 1), the power decreases as the voltage decreases. When above the noise threshold (point 2), the algorithm switches direction and increases the voltage (point 3). However, due to the hysteresis, the power has further decreased and hence the perturbation is switched again to backward scanning (point 4). As a result, large oscillations are created below the actual maximum power point. Orange: Modified algorithm that includes the power threshold regulation, showing reduced oscillations. Black arrows are backward scanning and red arrows forward scanning.

A first step towards optimizing the MPPT P\&O algorithm is to add thresholds ( $\varepsilon_{\text {backward }}$ and $\varepsilon_{\text {forward }}$ ) below which the power has to drop - compared to the previous local maxima - before switching direction (Figure 3, orange trace). Azab et al. have reported on similar hysteretic loop controllers, with the purpose of achieving faster transient response of the $\mathrm{P} \& \mathrm{O}[49]$. To the best of our knowledge, it is the first time that the issue of power tracking of inherently hysteretic solar cells is raised. Adding a hysteretic controller forces further scanning into forward bias before switching to backward scan. When the threshold is set too low (vide supra)the behavior of the modified algorithm converges to the standard one and the device will be tracked at a bias lower than optimal, whereas a threshold higher than necessary will induce unnecessary power oscillations that are detrimental to the average power output of the device. Such thresholds are usually not required for currently marketed PV technologies, since the $\mathrm{j}-\mathrm{V}$ relationship of silicon solar cells and most thin film technologies is usually bijective under moderate sampling rates (slower than the RC time constant or the solar cell), i.e. their conductance response features no low frequency complex component. In addition, the optimizations required to stabilize a DC measurement are different from the ones required in a switching converter, where the feedback parameter is usually a duty cycle change. Similar oscillations and instabilities have been recognized for the $\mathrm{P} \& \mathrm{O}$ algorithm when illuminations conditions are changing faster than the sampling rate[43], and hysteresis adds to this issue. Figure 4 shows an example of MPPT of a conventional bromide perovskite-based solar cell and compares it to a silicon solar cell without regulation (dashed black trace). Clearly, the perovskite cell works better with the power inversion threshold (blue trace) than without (green trace). Figure 5 shows the average power output (Figure 5a) and the oscillation intensity peaks (Figure $5 \mathrm{~b}$ ) as functions of the inversion threshold. The average power output of the solar cell is largely unaffected by the backward to forward threshold because of the 
direction of the hysteresis: when the device is switched from forward to backward scanning, the power immediately increases, hence the backward to forward threshold parameter is not required for stabilization. When this threshold is set too high, it becomes detrimental to the device performance: the device is scanned too far at voltages below $\mathrm{V}_{\mathrm{MPP}}$ before the scanning is inverted.

On the other hand we found that the power output is strongly correlated to $\varepsilon_{\text {forward }}$ (the forward to backward threshold). By preventing the device from switching too easily from forward to backward scan, oscillations can be avoided. Figure $5 \mathrm{c}$ depicts a similar experiment with a reference silicon device, where the absence of hysteresis means that the tracking is done best with the lowest threshold.

\section{Optimal performance through poling}

We found that for perovskite solar cells, the optimal set of oscillation thresholds is not the one that minimizes the oscillation, which is unexpected because setting the device at voltage away from the maximum power point is sub-optimal. An example of effective tracking with different forward to backward thresholds is shown for one device in Figure 5d. The average power output of the cell with strong oscillation in forward bias was found to be higher (3\% for the cell depicted in Figure $5 \mathrm{~d}$ ) than the cell with the lowest possible oscillation and over 30\% compared to the non-regulated algorithm. This effect is shown in Figure 5, where the circled regions highlight the optimal oscillation and the optimal power output for a $\mathrm{FAPbBr}_{3}$ based device and in Figure 4a, where the power output is plotted against time (blue trace versus red trace). This should come as no surprise as the $\mathrm{j}-\mathrm{V}$ cell measured from $V_{o c}$ to $J_{s c}$ usually shows better performance than when scanned from $J_{s c}$ to $V_{o c}$. This poling effect has already been discussed before and it has been suggested that migration of point defects could help charge extraction when the device is strongly biased in forward[50] Biasing temporary the device at voltages slightly higher than Vmpp could be used to enhance the power output of the cell during MPP tracking Induced perturbation can be easily implementable in any microcontroller-based MPPT that regulates the duty cycle of a DC/DC converter. To determine whether the average power increase upon oscillations around the MPP (shown in Figure 4a and 5d) results truly in increased collection efficiency, we compared the steady-state power output of a $10 \mathrm{~cm}^{2}$ (using a track \& hold algorithm) to the dynamic tracking described above at different slew rates (Figure 4b). The Results indicate that oscillations produce higher average power output that in the steady-state condition, but are conditioned to the drift of the device during the measurement. However, our observations show that efficient tracking with little oscillations (but not steady state) can be performed at very low slew rates using threshold values close to $0 \%$. As the scan rate increases, not only are threshold required to stabilize the algorithm (about $10 \%$ threshold is a good estimate), but also higher power is obtained through larger oscillations. In summary, similar power output can be obtained with fast tracking and large perturbations or slow tracking and low perturbation. 

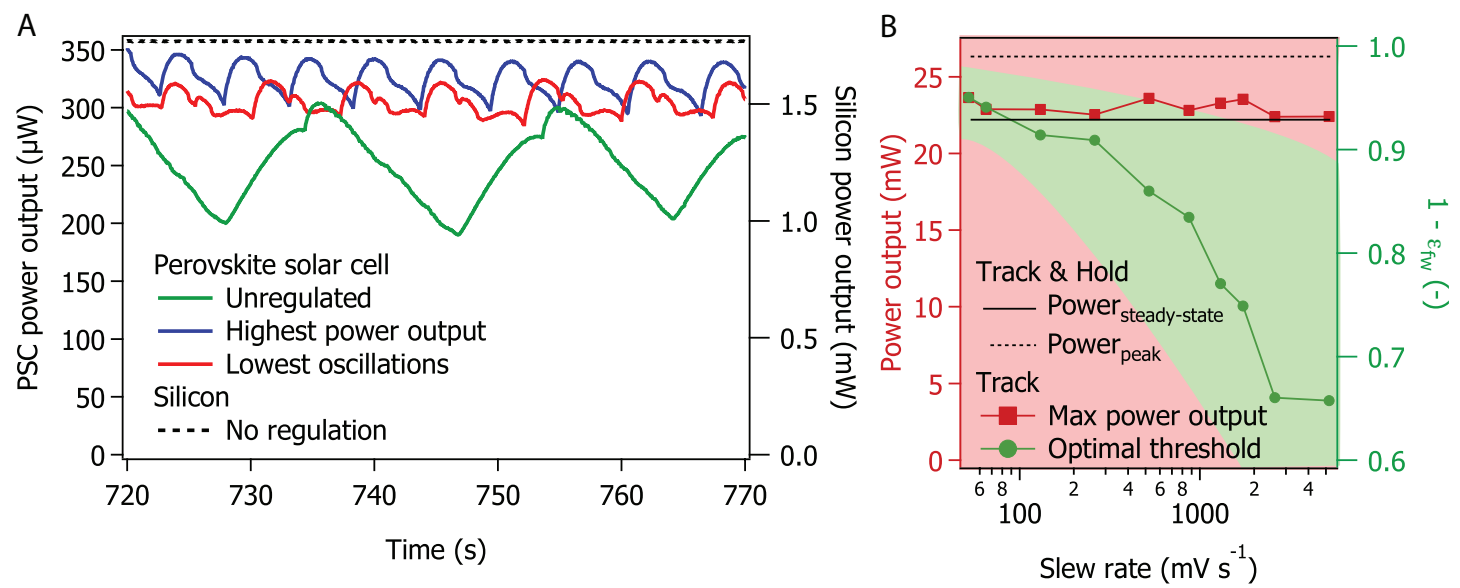

Figure 4: (a) MPPT of a $\mathrm{CH}_{3} \mathrm{NH}_{3} \mathrm{PbBr}_{3}$ solar cell (green, red, blue) and a crystalline silicon cell (black) in different conditions. Green: No threshold regulation. Red: lower attained oscillation. Blue: highest attained efficiency. The silicon cell was not regulated. (b) Red: Power output using the optimum forward to backward threshold of a $10 \mathrm{~cm}^{2}$ perovskite module as a function of the slew rate. Green: average threshold that yields the maximum power. The error bars represent the acceptable threshold values that generate at most $10 \%$ drop of the maximum power output (red curve). The red zone represent the zone where threshold lead to lower power output or instabilities and should be avoided.
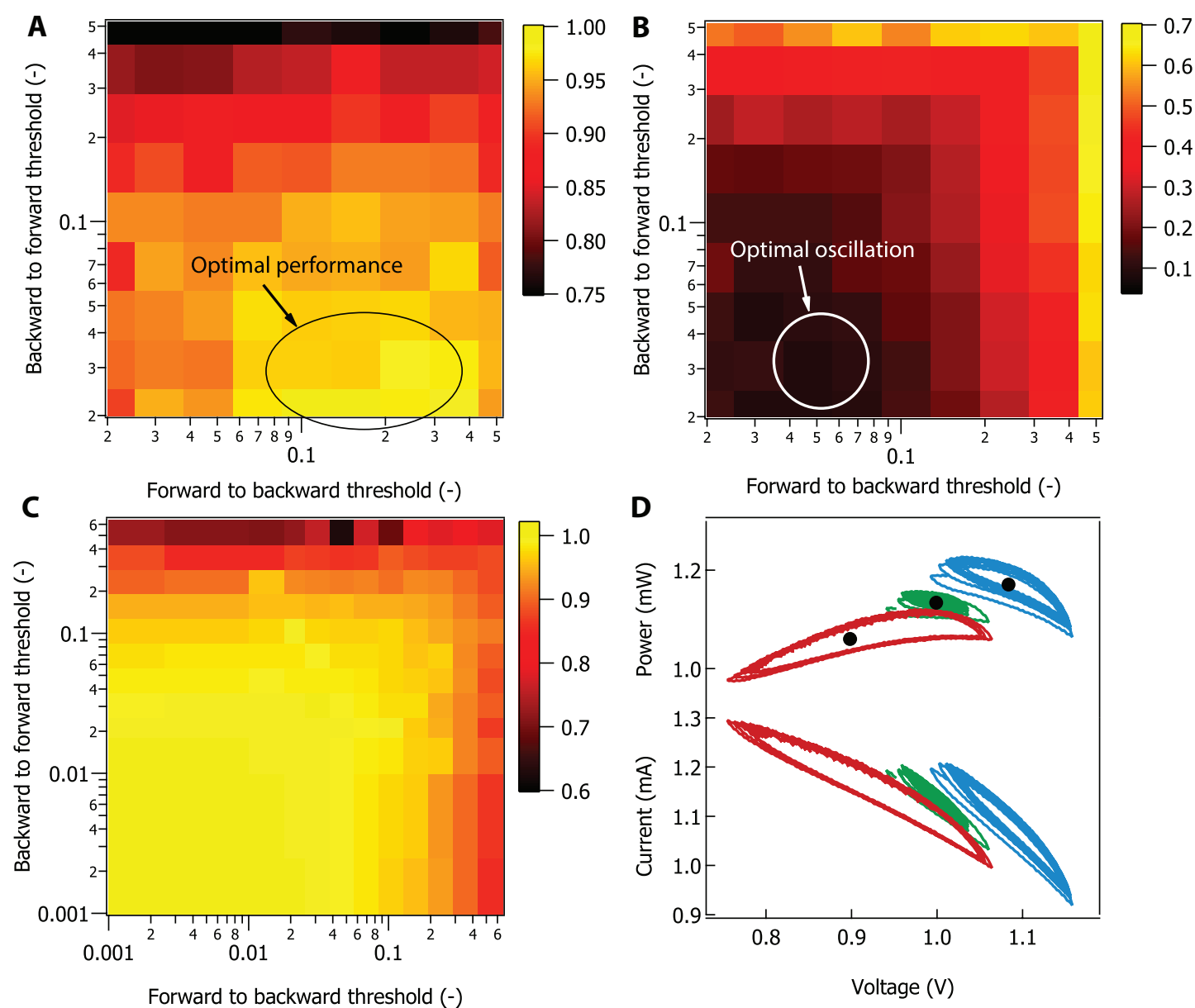
Figure 5: (a) Normalized power output of a $\mathrm{CH}_{3} \mathrm{NH}_{3} \mathrm{PbBr}_{3}$ solar cell as a function of the power thresholds $\varepsilon_{\text {backward }}$ and $\varepsilon_{\text {forward }}$. The circled area shows the region where the tracking parameters yield the highest averaged power output over 1 minute. Sampling of the matrix was performed randomly. (b) Peak-to-peak power oscillations of the algorithm (obtained simultaneously with figure $5 \mathrm{a}$, normalized to the maximum power output. The circled area shows the region where the tracking parameters are optimal in terms of reduction of the output oscillation. (c) Normalized power output of a reference silicon solar cell as a function of the power thresholds $\varepsilon_{\text {backward }}$ and $\varepsilon_{\text {forward }}$. The best regulation is obtained with the lowest possible thresholds. (d) j-V curves of the device used for figure 5a

and 3b, with different forward and backward power regulations. Red: $\varepsilon_{\text {backward }}=0.04 \%$, $\varepsilon_{\text {forward }}=0.32 \%$, green: $\varepsilon_{\text {backward }}=0.04 \%, \varepsilon_{\text {forward }}=2.56 \%$ and blue: $\varepsilon_{\text {backward }}=0.04 \%$, $\varepsilon_{\text {forward }}=10.24 \%$. The dots show the average power output of the cell at the average driving voltage.

\section{Stabilizing the algorithm at fast speeds}

Because the hysteresis of the solar is related to its complex impedance, the slew rate of the P\&O algorithm is expected to affect the tracking performance at steady state. The fundamental frequency of the MPP algorithm is given by equation 2.

$$
f_{1 s t}=\frac{S R}{2 V_{p p}}
$$

where $f_{1 s t}$ is the fundamental frequency of the triangular wave, SR is the slew rate $(\mathrm{V} / \mathrm{s})$ and $\mathrm{V}_{\mathrm{pp}}$ is the peak to peak voltage perturbation. A triangular wave contains harmonics over the whole frequency domain, of which the ones at high frequencies will show electronic capacitive storage and translate into the current response. In figure $6 a$ and $b$, we show the phase (Bode plot) and the impedance (Nyquist plot), respectively, acquired from a mesoporous $\mathrm{CH}_{3} \mathrm{NH}_{3} \mathrm{PbI}_{3}$-based solar cell at different bias. The usual low frequency Warburg-like feature was previously attributed to ionic polarization in the cell[46]. It spans from about $100 \mathrm{~Hz}$ down to less than $0.1 \mathrm{~Hz}$ with a local phase shift maximum between $0.2 \mathrm{~Hz}$ and $1 \mathrm{~Hz}$ depending on the bias. In the high frequency region spiro and perovskite contributions overlap in a single semicircle whilst the displacement from the origin of the plane over the real axes is the contribution of the substrate and gold resistance. The widespread complex conductance response of perovskite is the reason why normal $\mathrm{P} \& \mathrm{O}$ algorithms fail at low frequencies and predictably IncCond using the differential conductance from the ripple current and voltage of the DC/DC converter would fail if the large capacitance of perovskite solar cells are not taken into account.

In figure 6c, we show a parametric matrix showing power output as a function of the forward to backward threshold (x axis) and the slew rate (y axis). When the fundamental frequency of the MPP algorithm resonates with the slow response of the device impedance, higher power inversion thresholds need to be used to regulate the algorithm. For lower slew rates where the phase of the impedance 
should settle to $0^{\circ}$, lower thresholds can be used, and similar power output can be obtained. However, at slew rates below $0.1 \mathrm{~Hz}$, the algorithm would suffer from sudden changes in illumination and is therefore not optimal for the outdoor environment. The best performing P\&O algorithm could sample at frequencies where the phase of the Bode impedance is closest to 0 , between the first and the second arc. It is important to note that during the ageing of the device, its frequency response might change. In this case making the tracking frequency adaptive could be a further modification required for an effective and efficien power extraction.

The slow response of the device would then be treated as a change in mean efficiency. Modifications of the proposed maximum power point tracking setup are underway to increase the sampling rate to 20kSPS, which will allow tracking at frequencies up to $1 \mathrm{kHz}$.

A
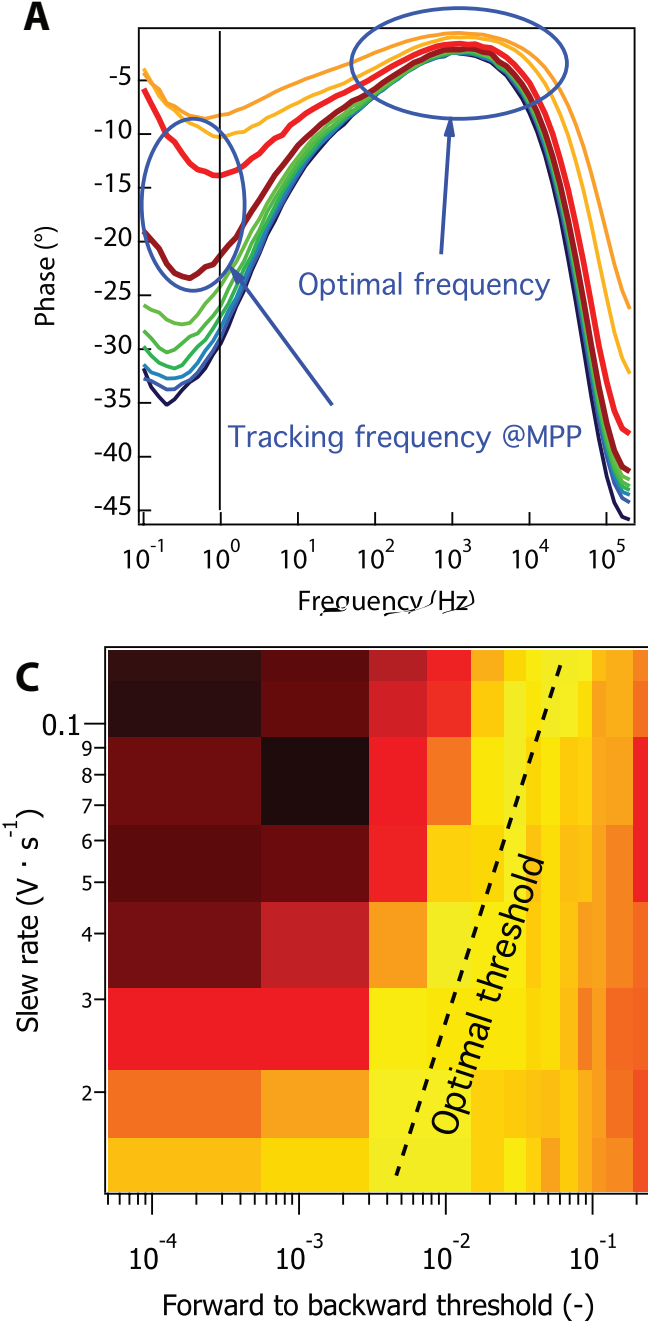

B
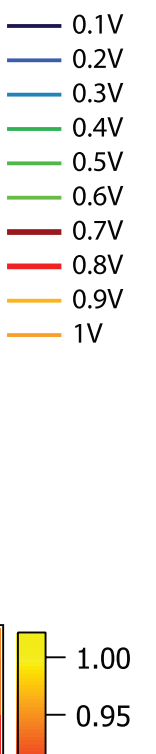

$-0.90$

$-0.85$

$-0.80$

$-0.75$

$-0.70$

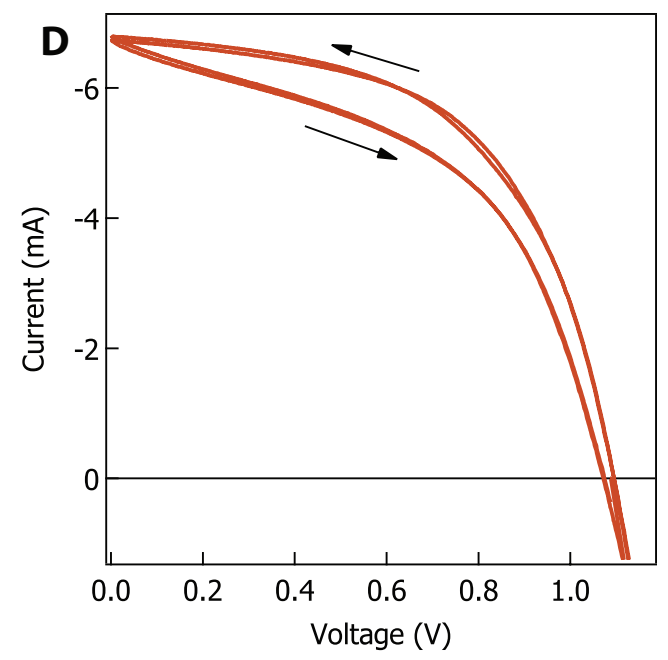

Figure 6: (a) Bode plot of the impedance phase of an $\mathrm{m}-\mathrm{TiO}_{2} / \mathrm{CH}_{3} \mathrm{NH}_{3} \mathrm{PbI} / \mathrm{Spiro}-\mathrm{MeOTAD}$ solar cell under an equivalent $10 \%$ illumination by a white LED. (b) Nyquist plot of the impedance for the same cell illuminated in the same conditions. (c) Averaged power output of the device under maximum power power tracking, using the illumination intensity; plotted as a function of the forward to backward threshold ( $x$ axis) and slew rate (y axis). (d) $j-V$ relationship of the device scanned in both directions, under illumination, at $200 \mathrm{mV} \mathrm{s}$.

\section{Conclusion}


We have shown that tracking the maximum power of a perovskite cell is challenging due to the low frequency response of PSCs. To alleviate the hysteretic response and non-optimal power tracking, an arbitrarily defined power inversion threshold is introduced into the classical perturb-and-observe algorithm, which forces the device into a regime of controlled oscillation of more than $10 \%$ of the average power, which does not necessarily come at the expense of power output. Such a method can be employed for larger area PV arrays by affecting the duty cycle of the DC-DC in a similar manner. Whether temporary poling can result in overall higher power output is currently under research. Moreover measuring and improving the stability of perovskite laboratory cell has become an urgent task. Often the means to perform correctly ageing tests on long time scales are lacking within research groups. We have reported the conception and realization of an inexpensive acquisition board capable of maximum power point tracking and $\mathrm{j}-\mathrm{V}$ sweeps and released the schematics in the Supplementary Information.

\section{Acknowledgements}

M.G thanks the Max Planck Society for a Max Planck Fellowship at the MPI for Solid State Research in Stuttgart, Germany. MG and NP acknowledge financial support from the European Union Seventh Framework Program (FP7/2007-2013) under grant agreement name "GLOBASOL" and from the Swiss National Foundation under grant number "IZLRZ2_164061".

Experimental procedures

Light source

In all cases, the light source consisted of an array of white LEDs powered by a constant current. Equivalent sun intensities were calibrated using a calibrated Si reference diode equipped with a KG-3 filter.

\section{Impedance response and Lissajous curves}

Impedance response were recorded using a Biologic SP-300 equipped with a frequency response analyzer module. Devices were illuminated by a single LED (Luxeonstar 5650K) powered by a DC current source. The same illumination source was used for the Lissajous curves, where the sinusoidal perturbation $(22 \mathrm{mV}$ RMS) on top of a DC bias $(950 \mathrm{mV})$ was provided by a function generator (AFG 3022). The current response was amplified by home-made current to voltage amplifier (based on INA217, gain of 200V/V), and both voltage and current output were recorded on an oscilloscope (DPO 7104).

\section{Device fabrication}

Bromide based devices

FAPbBr3 device fabrication: All materials were purchased from Sigma-Aldrich or Acros Organics and were used as received. FAPbBr3 films were deposited using sequential deposition method. 1.2 $\mathrm{M} \mathrm{PbBr} 2$ precursor solution in DMF+DMSO mixture (1:1 volume ratio) was prepared by constant stirring at $60{ }^{\circ} \mathrm{C}$ for $30 \mathrm{~min}$. $50 \mathrm{uL}$ of $1.2 \mathrm{M} \mathrm{PbBr} 2$ precursor solution was spin coated onto the 
mesoporous $\mathrm{TiO} 2$ films at $3000 \mathrm{rpm}$ for $30 \mathrm{~s}$. This was followed by annealing the films at $80{ }^{\circ} \mathrm{C}$ for 15 min. After cooling to room temperature, the $\mathrm{PbBr} 2$ films were dipped into isopropanol solution of $\operatorname{FABr}(50 \times 10-3 \mathrm{~m})$ for $5 \mathrm{~min}$ at $60{ }^{\circ} \mathrm{C}$, rinsed with 2-propanol for $5 \mathrm{~s}$ and dried at $80{ }^{\circ} \mathrm{C}$ for 30 min. Spiro-OMeTAD as HTM was deposited by spin coating $40 \mu \mathrm{L}$ of the prepared solution at 4000 rpm for $30 \mathrm{~s}$. The HTM solution was prepared by dissolving $72.3 \mathrm{mg}$ (2,2',7,7'-tetrakis(N,N-di-pmethoxyphenylamine)-9,9-spirobifluorene) (spiro-OMeTAD), $17.5 \mu \mathrm{L}$ of a stock solution of $520 \mathrm{mg} \mathrm{mL}-1$ bis(trifluoromethylsulphonyl)imide in acetonitrile, and $29 \mu \mathrm{L}$ of a stock solution of $300 \mathrm{mg} \mathrm{mL}-1$ tris(2-(1H-pyrazol-1-yl)-4-tert-butylpyridine)cobalt(III)

bis(trifluoromethylsulphonyl)imide in acetonitrile, and $28.8 \mu \mathrm{L}$ 4-tert-butylpyridine in $1 \mathrm{~mL}$ chlorobenzene. The device fabrication was carried out under controlled atmospheric conditions with humidity $<2 \%$. Finally, device fabrication was completed by thermally evaporating $70 \mathrm{~nm}$ of gold layer as a back contact.

\section{$\left(\mathrm{FAPbI}_{3}\right)_{0.85}\left(\mathrm{MAPbBr}_{3}\right)_{0.15}$ Based devices}

Fluorine-doped tin oxide (FTO) glass was etched to form the two detached electrodes with zinc powder and diluted hydrochloric acid. The glass was then cleaned by sonication in $2 \%$ Hellmanex solution. Thereafter, the glass substrates were rinsed with deionized water and Ethanol and dried with compressed air and subject to UV-Ozone treatment for $15 \mathrm{~min}$.

A compact hole blocking layer of $\mathrm{TiO} 2$ was deposited onto the glass by spray pyrolysis. The precursor solution consisted of $600 \mu \ell$ of titanium diisopropoxide bis(acetylacetonate), $400 \mu \ell$ of acetylacetone in $9 \mathrm{~mL}$ of ethanol, which was then sprayed with the carrier gas oxygen at $450 \mathrm{C}$. A scaffold of mesoporous $\mathrm{TiO} 2(\mathrm{~m}-\mathrm{TiO} 2)$ was depositedby spin coating a 1:5 (w/w) dispersion of $\mathrm{TiO} 2$ with particle size of $30 \mathrm{~nm}$ in Ethanol at $4000 \mathrm{rpm}$ for $10 \mathrm{sec}$ to maintain a thickness of about $300 \mathrm{~nm}$. The thus formed films were then heated upto $450 \mathrm{C}$ and sintered at that temperature for $30 \mathrm{~min}$ and allowed to cool to 100 C. A surface treatment of the m-TiO2 was carried out by spincoating a solution of $10 \mathrm{mg} / \mathrm{mL}$ of Bis(trifluoromethane)sulfonimide lithium salt in Acetonitrile at $3000 \mathrm{rpm}$ for $10 \mathrm{sec}$. The substrates were then baked again by the procedure described above. The substrates were then baked again by the procedure described above. The cooled substrates were then used for the deposition of perovskite upon them.

Upon cooling to room temperature, the perovskite layer was deposited in a dry air-filled glovebox by spin coating the perovskite precursor solution. The latter consisted in a solution containing FAI (1 M), $\mathrm{PbI}_{2}(1.1 \mathrm{M}), \mathrm{MABr}(0.2 \mathrm{M})$ and $\mathrm{PbBr}_{2}(0.2 \mathrm{M})$ in anhydrous dimethylformamide/ dimethylsulphoxide $(4: 1(\mathrm{v}: \mathrm{v}))$ solution. The perovskite solution was spin coated in a two-step program at 1,000 and 6,000 r.p.m. for 10 and 30 s, respectively. During the second step, $120 \mu 1$ of clorobenzene was poured on the spinning substrate $10 \mathrm{~s}$ prior the end of the program. The substrates were then annealed at $100{ }^{\circ} \mathrm{C}$ for $1 \mathrm{~h}$ in nitrogen-filled glove box.

The HTM was subsequently deposited on the top of the perovskite layer by spin coating its solution at $4000 \mathrm{rpm}$ for $20 \mathrm{~s}$ with a ramp of $2000 \mathrm{rpm} \mathrm{s}-1$. To the prepared solution of $50 \mathrm{mg}$ of spiro-OMeTAD in $574 \mu \ell$ of $\mathrm{CB}, 20 \mathrm{uL}$ of tert-butylpyridine, $11.4 \mu \ell$ of $1.8 \mathrm{M}$ LiTFSI in acetonitrile and $4.9 \mu \ell$ of 0.25M Cobaltsalt (FK 209)in Acetonitrile were added as dopants. 
Finally, device fabrication was completed by thermally evaporating $70 \mathrm{~nm}$ of gold layer as a back contact.

Reference

1. Kojima, A., Teshima, K., Shirai, Y., and Miyasaka, T. (2009) Organometal halide perovskites as visible-light sensitizers for photovoltaic cells. J. Am. Chem. Soc., 131 (17), 6050-1.

2. Kontos, A.G., Stergiopoulos, T., Likodimos, V., et al. (2013) Long-Term Thermal Stability of Liquid Dye Solar Cells. J. Phys. Chem. C, 117 (17), 8636-8646.

3. Asghar, M.I., Miettunen, K., Halme, J., et al. (2010) Review of stability for advanced dye solar cells. Energy Environ. Sci., 3 (4), 418.

4. Harikisun, R., and Desilvestro, H. (2011) Long-term stability of dye solar cells. Sol. Energy, 85 (6), 1179-1188.

5. Marszalek, M., Arendse, F.D., Decoppet, J.-D., et al. (2014) Ionic Liquid-Sulfolane Composite Electrolytes for High-Performance and Stable Dye-Sensitized Solar Cells. Adv. Energy Mater., $4(6), \mathrm{n} / \mathrm{a}-\mathrm{n} / \mathrm{a}$.

6. Kakavelakis, G., Konios, D., Stratakis, E., and Kymakis, E. (2014) Enhancement of the Efficiency and Stability of Organic Photovoltaic Devices via the Addition of a LithiumNeutralized Graphene Oxide Electron-Transporting Layer. Chem. Mater., 26 (20), 5988-5993.

7. Reese, M.O., Gevorgyan, S.A., Jørgensen, M., et al. (2011) Consensus stability testing protocols for organic photovoltaic materials and devices. Sol. Energy Mater. Sol. Cells, 95 (5), 1253-1267.

8. NREL Best Research-Cell Efficiencies.

9. Chen, W., Wu, Y., Yue, Y., et al. (2015) Efficient and stable large-area perovskite solar cells with inorganic charge extraction layers. Science (80-. )., 350 (6263), 944-948.

10. Saliba, M., Matsui, T., Seo, J.-Y., et al. (2016) Cesium-containing triple cation perovskite solar cells: improved stability, reproducibility and high efficiency. Energy Environ. Sci.

11. Tress, W., Marinova, N., Moehl, T., et al. (2015) Understanding the rate-dependent J-V hysteresis, slow time component, and aging in $\mathrm{CH} 3 \mathrm{NH} 3 \mathrm{PbI} 3$ perovskite solar cells: the role of a compensated electric field. Energy Environ. Sci., 8 (3), 995-1004.

12. Unger, E.L., Hoke, E.T., Bailie, C.D., et al. (2014) Hysteresis and transient behavior in current-voltage measurements of hybrid-perovskite absorber solar cells. Energy Environ. Sci., 7 (11), 3690-3698.

13. Zhang, L. (2000) Real-time maximum power point tracking for grid-connected photovoltaic systems. 8th Int. Conf. Power Electron. Var. Speed Drives, 2000, 124-129.

14. Wasynezuk, O. (1983) Dynamic Behavior of a Class of Photovoltaic Power Systems. IEEE Trans. Power Appar. Syst., PAS-102 (9), 3031-3037.

15. Tafticht, T., and Agbossou, K. Development of a MPPT method for photovoltaic systems. Can. Conf. Electr. Comput. Eng. 2004 (IEEE Cat. No.04CH37513), 1123-1126.

16. Jung, Y., Yu, G., Choi, J., and Choi, J. High-frequency DC link inverter for grid-connected photovoltaic system. Conf. Rec. Twenty-Ninth IEEE Photovolt. Spec. Conf. 2002., 1410-1413.

17. Jain, S., and Agarwal, V. (2004) A New Algorithm for Rapid Tracking of Approximate Maximum Power Point in Photovoltaic Systems. IEEE Power Electron. Lett., 2 (1), 16-19.

18. Hua, C.-C., and Jong-Rong Lin Fully digital control of distributed photovoltaic power systems. ISIE 2001. 2001 IEEE Int. Symp. Ind. Electron. Proc. (Cat. No.01TH8570), 1, 1-6.

19. Femia, N., Petrone, G., Spagnuolo, G., and Vitelli, M. (2005) Optimization of Perturb and Observe Maximum Power Point Tracking Method. IEEE Trans. Power Electron., 20 (4), $963-$ 973.

20. Al-Amoudi, A. (1998) Optimal control of a grid-connected PV system for maximum power 
point tracking and unity power factor. Seventh Int. Conf. Power Electron. Var. Speed Drives, 1998, 80-85.

21. D'Souza, N.S., and Lopes, L.A.C. An Intelligent Maximum Power Point Tracker Using Peak Current Control. IEEE 36th Conf. Power Electron. Spec. 2005., 172.

22. Chiang, M.-L., Hua, C.-C., and Lin, J.-R. Direct power control for distributed PV power system. Proc. Power Convers. Conf. 2002 (Cat. No.02TH8579), 1, 311-315.

23. Chomsuwan, K., Prisuwanna, P., and Monyakul, V. Photovoltaic grid-connected inverter using two-switch buck-boost converter. Conf. Rec. Twenty-Ninth IEEE Photovolt. Spec. Conf. 2002., $1527-1530$.

24. Brambilla, A., Gambarara, M., Garutti, A., and Ronchi, F. New approach to photovoltaic arrays maximum power point tracking. 30th Annu. IEEE Power Electron. Spec. Conf. Rec. (Cat. No.99CH36321), 2, 632-637.

25. Hussein, K.H., Muta, I., Hoshino, T., and Osakada, M. (1995) Maximum photovoltaic power tracking: an algorithm for rapidly changing atmospheric conditions. IEE Proc. - Gener. Transm. Distrib., 142 (1), 59.

26. Irisawa, K., Saito, T., Takano, I., and Sawada, Y. Maximum power point tracking control of photovoltaic generation system under non-uniform insolation by means of monitoring cells. Conf. Rec. Twenty-Eighth IEEE Photovolt. Spec. Conf. - 2000 (Cat. No.00CH37036), 17071710 .

27. Yeong-Chau Kuo, Tsorng-Juu Liang, and Jiann-Fuh Chen (2001) Novel maximum-powerpoint-tracking controller for photovoltaic energy conversion system. IEEE Trans. Ind. Electron., 48 (3), 594-601.

28. Kobayashi, K., Takano, I., and Sawada, Y. A study on a two stage maximum power point tracking control of a photovoltaic system under partially shaded insolation conditions. 2003 IEEE Power Eng. Soc. Gen. Meet. (IEEE Cat. No.03CH37491), 2612-2617.

29. Yu, G.J., Jung, Y.S., Choi, J.Y., et al. A novel two-mode MPPT control algorithm based on comparative study of existing algorithms. Conf. Rec. Twenty-Ninth IEEE Photovolt. Spec. Conf. 2002., 1531-1534.

30. Salas, V., Olías, E., Barrado, A., and Lázaro, A. (2006) Review of the maximum power point tracking algorithms for stand-alone photovoltaic systems. Sol. Energy Mater. Sol. Cells, 90 (11), 1555-1578.

31. Wilamowski, B.M., and Xiangli Li Fuzzy system based maximum power point tracking for PV system. IEEE 2002 28th Annu. Conf. Ind. Electron. Soc. IECON 02, 3280-3284.

32. Mahmoud, A.M.A., Mashaly, H.M., Kandil, S.A., et al. Fuzzy logic implementation for photovoltaic maximum power tracking. Proc. 9th IEEE Int. Work. Robot Hum. Interact. Commun. IEEE RO-MAN 2000 (Cat. No.00TH8499), 155-160.

33. Simoes, M.G., Franceschetti, N.N., and Friedhofer, M. A fuzzy logic based photovoltaic peak power tracking control. IEEE Int. Symp. Ind. Electron. Proceedings. ISIE'98 (Cat. No.98TH8357), 1, 300-305.

34. Senjyu, T., and Uezato, K. Maximum power point tracker using fuzzy control for photovoltaic arrays. Proc. 1994 IEEE Int. Conf. Ind. Technol. - ICIT '94, 143-147.

35. Hilloowala, R.M., and Sharaf, A.M. A rule-based fuzzy logic controller for a PWM inverter in photo-voltaic energy conversion scheme. Conf. Rec. 1992 IEEE Ind. Appl. Soc. Annu. Meet., $762-769$.

36. Hiyama, T., Kouzuma, S., and Imakubo, T. (1995) Identification of optimal operating point of PV modules using neural network for real time maximum power tracking control. IEEE Trans. Energy Convers., 10 (2), 360-367.

37. Kyoungsoo Ro, and Rahman, S. (1998) Two-loop controller for maximizing performance of a grid-connected photovoltaic-fuel cell hybrid power plant. IEEE Trans. Energy Convers., 13 (3), 276-281.

38. Hussein, A., Hirasawa, K., Jinglu Hu, and Murata, J. The dynamic performance of photovoltaic supplied de motor fed from DC-DC converter and controlled by neural networks. Proc. 2002 
Int. Jt. Conf. Neural Networks. IJCNN'02 (Cat. No.02CH37290), 607-612.

39. Midya, P., Krein, P.T., Turnbull, R.J., et al. Dynamic maximum power point tracker for photovoltaic applications. PESC Rec. 27th Annu. IEEE Power Electron. Spec. Conf., 2, 17101716 .

40. Enslin, J.H.R., and Snyman, D.B. Simplified feed-forward control of the maximum power point in PV installations. Proc. 1992 Int. Conf. Ind. Electron. Control. Instrumentation, Autom., 548-553.

41. Kislovski, A.S., and Redl, R. Maximum-power-tracking using positive feedback. Proc. 1994 Power Electron. Spec. Conf. - PESC'94, 1065-1068.

42. Slonim, M.A., and Rahovich, L.M. Maximum power point regulator for $4 \mathrm{~kW}$ solar cell array connected through invertor to the AC grid. IECEC 96. Proc. 31st Intersoc. Energy Convers. Eng. Conf., 3, 1669-1672.

43. Femia, N., Petrone, G., Spagnuolo, G., and Vitelli, M. (2005) Optimization of Perturb and Observe Maximum Power Point Tracking Method. IEEE Trans. Power Electron., 20 (4), $963-$ 973.

44. Esram, T., and Chapman, P.L. (2007) Comparison of Photovoltaic Array Maximum Power Point Tracking Techniques. IEEE Trans. Energy Convers., 22 (2), 439-449.

45. Esram, T., Kimball, J.W., Krein, P.T., et al. (2006) Dynamic Maximum Power Point Tracking of Photovoltaic Arrays Using Ripple Correlation Control. IEEE Trans. Power Electron., 21 (5), 1282-1291.

46. Yang, T.-Y., Gregori, G., Pellet, N., et al. (2015) The Significance of Ion Conduction in a Hybrid Organic-Inorganic Lead-Iodide-Based Perovskite Photosensitizer. Angew. Chemie Int. Ed., 54 (27), 7905-7910.

47. Latham, A.M., Sullivan, C.R., and Odame, K.M. (2010) Performance of photovoltaic maximum power point tracking algorithms in the presence of noise. IEEE Energy Convers. Conf. Expo.

48. Dallago, E., Finarelli, D.G., Gianazza, U. Pietro, et al. (2013) Theoretical and Experimental Analysis of an MPP Detection Algorithm Employing a Single-Voltage Sensor Only and a Noisy Signal. IEEE Trans. Power Electron., 28 (11), 5088-5097.

49. Azab, M. (2008) A New Maximum Power Point Tracking for Photovoltaic Systems . Int. J. Electr. Comput.Energ. Electron. Commun.Eng., 2, 1599-1603 EM -pe_bhit@yahoo.com, mohazab@lycos.c.

50. O'Regan, B.C., Barnes, P.R.F., Li, X., et al. (2015) Optoelectronic Studies of Methylammonium Lead Iodide Perovskite Solar Cells with Mesoporous TiO 2 : Separation of Electronic and Chemical Charge Storage, Understanding Two Recombination Lifetimes, and the Evolution of Band Offsets during J - V Hysteresis. J. Am. Chem. Soc., 137 (15), 50875099 . 


\section{Supplementary Information}

\section{Electronic instrumentation}

Solutions for multiple channels acquisition cards already exist and are widely available commercially. However, the cost of such instruments is usually prohibitive for large batches of solar cells, and offer capabilities beyond the requirements for long-term testing of solar cells (fast acquisition, wide voltage and current range, 24-bit resolution, ...). Standards ask for 1'000 hours of continuous uninterrupted testing under constant sunlight, which is clearly problematic when hundreds of devices have to be measured. The degradation pathways of $3^{\text {rd }}$ generation solar cells, including perovskite cells, often remain under debate. In the case of hybrid organic-inorganic perovskites, humidity and solvent-induced degradation is often cited as the main problem, but other issues such as phase segregation, ion migration and crystallization are also likely to participle to the degradation of performances. Fixing such issues require large ageing facilities. A multi-channel ageing setup is an attractive solution because it allows the establishment of a statistical basis by parallel testing of various device architectures, testing conditions or packaging (sealing, sizing, ...).. We report on a relatively inexpensive and elegant system that can replace most potentiostats or source-measuring units for the measurement and tracking of solar cells. In this Supplemetary Information, we release the schematics, bill of material, cost estimate and microcontroller code.

When testing the stability of large modules with high photocurrent and high voltages, a buck-boost converter is usually required, such that the power output of the PV array is harvested by an external load (for DC loading) - typically a thermal resistance with a heat sink - or to an inverter, for DC/AC conversion. However provided that the device delivers small photocurrents (in our case, less than $60 \mathrm{~mA}$ in total) and low voltages, the power generated can be easily dissipated into heat in the output stage of the driving unit. In our case, we chose an operational amplifier in follower configuration (OPA2192), placed within the feedback loop of the precision driver (INA2132), to compensate for drifts in temperature and non-unity gain. A digital to analog converter (DAC7563), interfaced by a microcontroller (ATMega328), sources the reference voltage that is driven by the output stage to the device. To sense the sinking or sourcing current, a small resistance $(0.5 \mathrm{Ohm})$ is positioned in series with the device (high side), and the voltage drop across this resistor is amplified by a low-noise, high gain $(200 \mathrm{~V} / \mathrm{V})$ instrument amplifier (INA188) to feed into a $4^{\text {th }}$ order Butterworth low-pass filter (OPA4722) that serves both anti-aliasing and high frequency noise removal. The cut-off frequency of the filter typically limits the sampling rate of the instrument and we set it arbitrarily to $500 \mathrm{~Hz}$ so that it would settle within 1 bit resolution in roughly $1 \mathrm{~ms}$. The output of the filter is fed into a 16 bit $\Delta \Sigma$ analog-to-digital converter (ADS1118) for the sampling, also interfaced by the microcontroller. The voltage across the device is directly buffered (OPA2188) into the low pass filter and sampled on a second channel of the ADC after appropriate level shifting. For cost saving, the 16 sensing lines ( 8 for current, 8 for voltage) are multiplexed (CD54HC4051) into the low pass filter and sampled by the same ADC. However, the drive line (DAC7563 DAC, INA2132 level shifter and OPA2191 output driver) are individual to each pair of cells (those three parts have two channel each), and therefore the voltage across each device is constantly maintained, even though not sample In our case, the microcontroller is 
an inexpensive, open-source and easily programmable Arduino Nano, mounted onto the board. When all the devices are connected together, a bandwidth of about $3 \mathrm{~Hz}$ can be achieved, typically limited by the Butterworth filter, the sampling rate of the ADC and the data transfer. Changing the $-3 \mathrm{db}$ pole of the Butterworth filter and using a faster ADC could easily achieve faster tracking.

Using a 16bit analog to digital converter allowed us to read voltage up to 15.5 bit resolution and a 15 bit current resolution. The value of the series resistance, the gain of the INA and the (programmable) gain of the ADC allow wide tuning of the current range. The INA188 being of relatively low noise $(12 n V / \sqrt{H z})$ allow for large amplification. For this particular 16 bit resolution A/D converter with a Full-scale-range at $+/-2.048 \mathrm{~V}$, the input-referred RMS noise is $62.5 \mu \mathrm{V}$. Therefore, a gain of

$$
G=\frac{62.5}{0.012 \cdot \sqrt{500}}=233 \mathrm{~V} / \mathrm{V}
$$

at the INA will remain within the boundaries of the A/D noise. A lower gain will reduce the system noise, but larger series resistance will have to be used to cover the same current range. Larger gains will begin to affect the effective number of bits (ENOB). Selecting a gain of $200 \mathrm{~V} / \mathrm{V}$ and a current range of $+/-20 \mathrm{~mA}$ sets the series resistance to $0.5 \mathrm{Ohm}$, which creates a negligible voltage drop $(5 \mathrm{mV}$ at $10 \mathrm{~mA}$ ) and can be compensated by the acquisition system. The effective number of bits for this configuration is shown in Figure SI 1.

Based on the noise figure, a resolution of about $880 \mathrm{nA}$ can be achieved. In practice however, the nonlinearity of the gain (INA, filter and ADC) will predominate. The integral non-linearity of the voltage sensing and current sensing is shown in Figure SI $2(a, b)$. The INL of the current sensing reduces the resolution by $24 \mathrm{LSB}$, which brings the resolution to 11.4 ENOB. The accuracy of the voltage sensing could be greatly improved by fitting the calibration curve to the region of interest (negative currents, photovoltaic mode). The non-linearity of the voltage sensing stays under the resolution of the D/A converter, i.e. $1 \mathrm{mV}$ and better resolution can not be expected without selecting a 14 or 16-bit DAC.
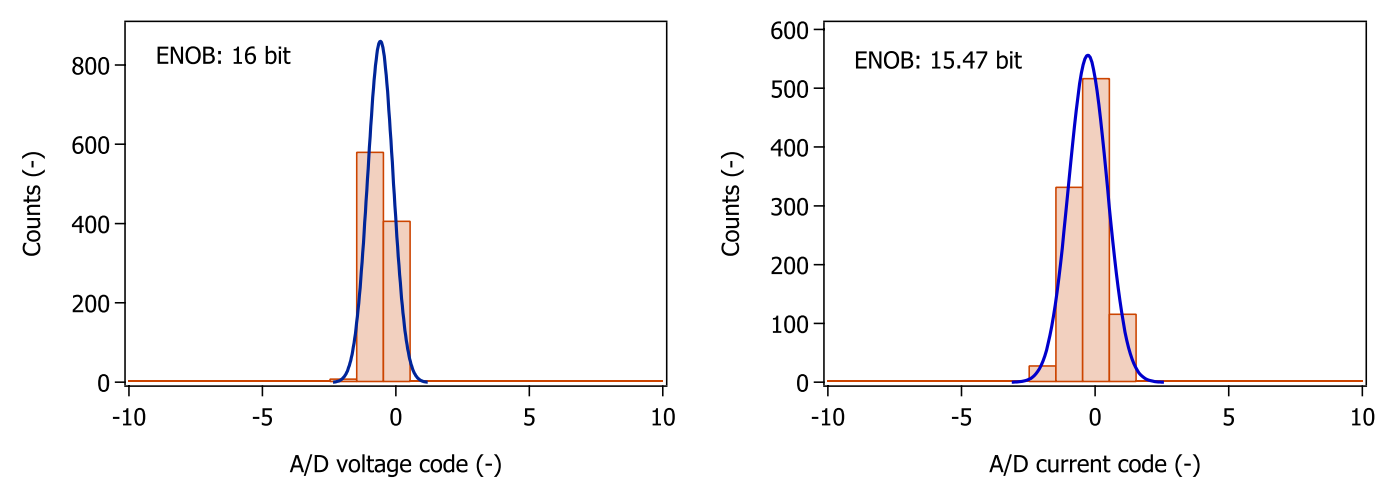

Figure SI 1: Noise performance of the sensing lines. The ENOB resolution is calculated from the RMS noise of the analog to digital converter, obtained by approximating the histograms by a normal distribution (a) Voltage code histogram ( $N=1000$ counts) for a typical sensing channel. The calculated effective number of bits was 16 (b) Current code histogram $(N=1000$ counts) for a typical sensing channel. The effective number of bit was 15.47. 

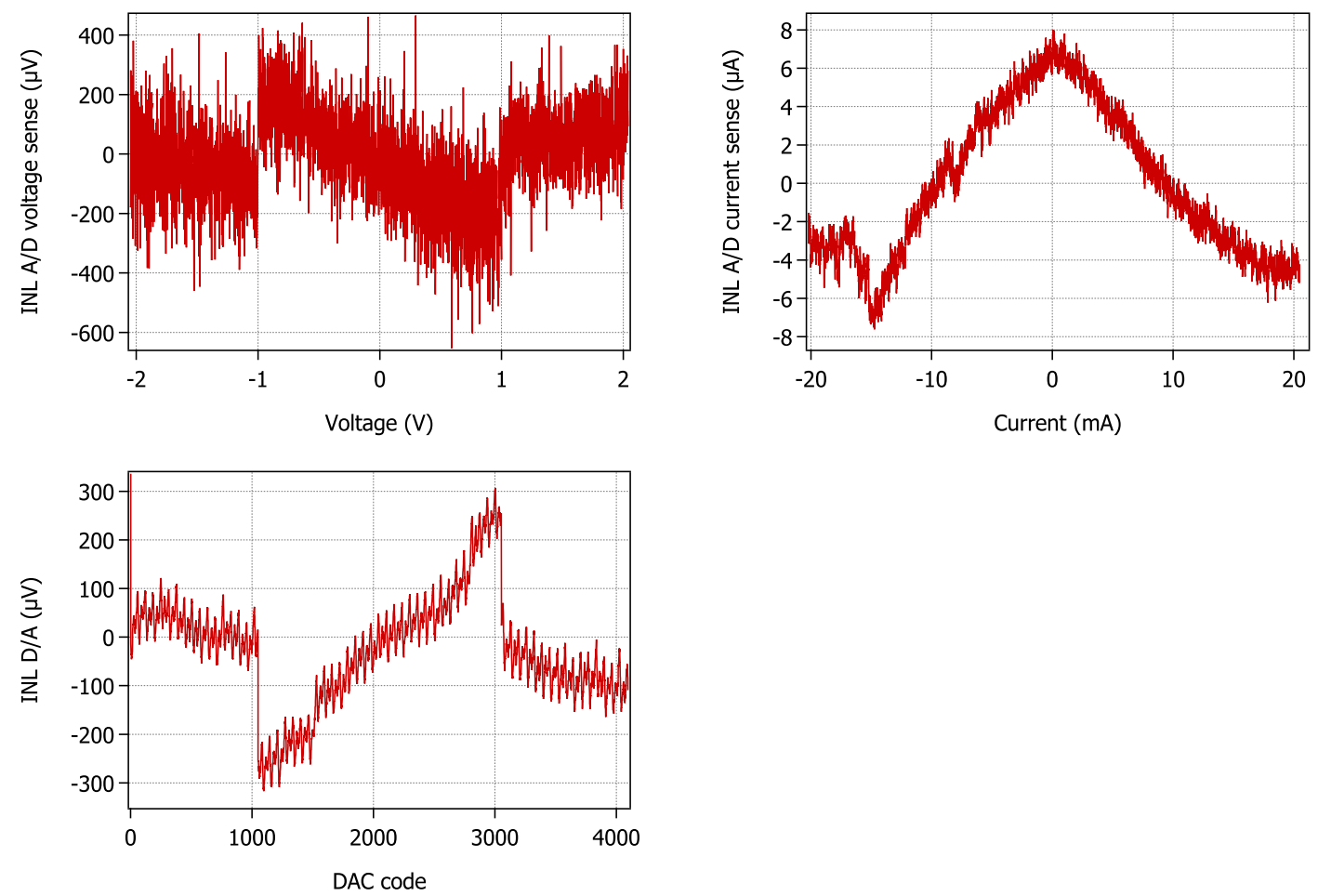

Figure SI 2: Integral non-linearity (INL) of the (a) voltage sensing, (b) current sensing and (c) voltage driving. Obtained as the residuals of the fit through the whole ADC and DAC code range.

The dynamic performances of the DAC drive are shown in Figure SI 3. Typical slew rates of $0.15 \mathrm{~V} / \mu \mathrm{s}$ were recorded (Figure SI 3a), limited by the INA2132 $(0.1 \mathrm{~V} / \mu \mathrm{s}$ in the data sheet). The speed of the voltage step is deemed largely sufficient with regards to the frequency of the reading. Cross talks between two neighboring channels (using the same DAC, INA2132 and OPA2192) is shown in Figure SI 3b. No significant perturbation of the voltage on the second channel was observed upon sudden voltage change in the first channel. Similarly, no significant perturbation in the sensing was observed (Figure SI 3c)
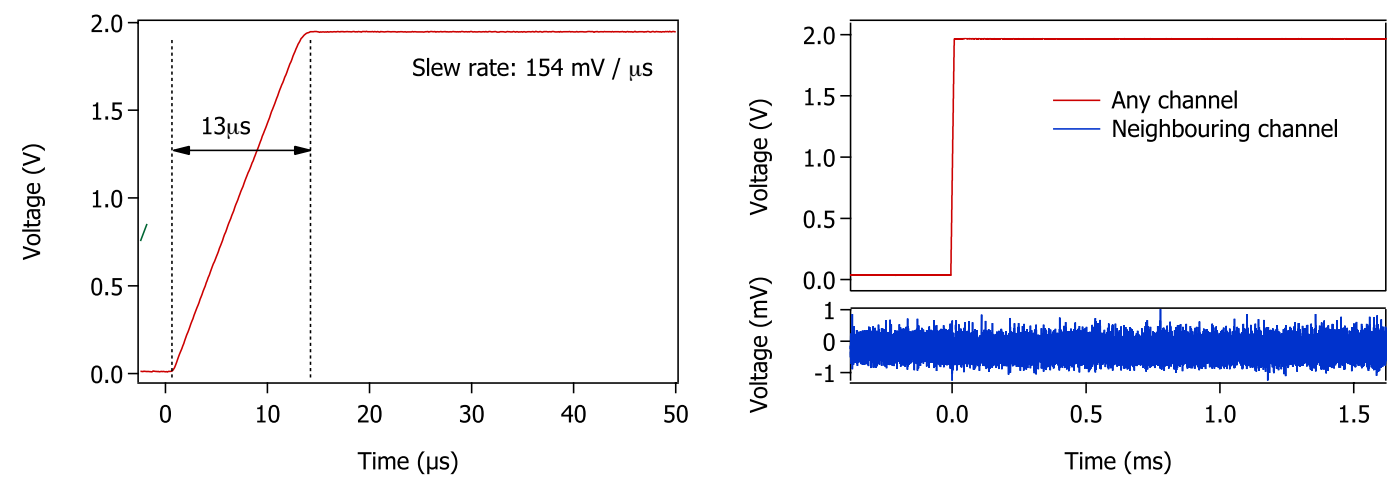


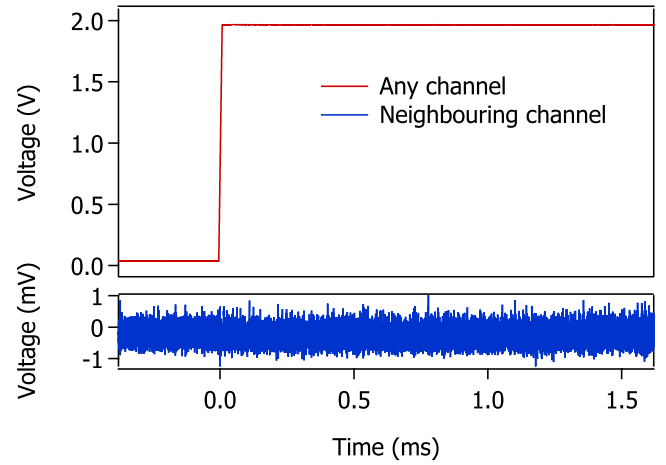

Figure SI 3: Dynamic performances of the MPPT setup. (a) Large signal settling from code 2048 to 4096. (b) Drive line cross-talk between two neighboring channels. (c) Sense line cross-talk between two neighbouing channels 


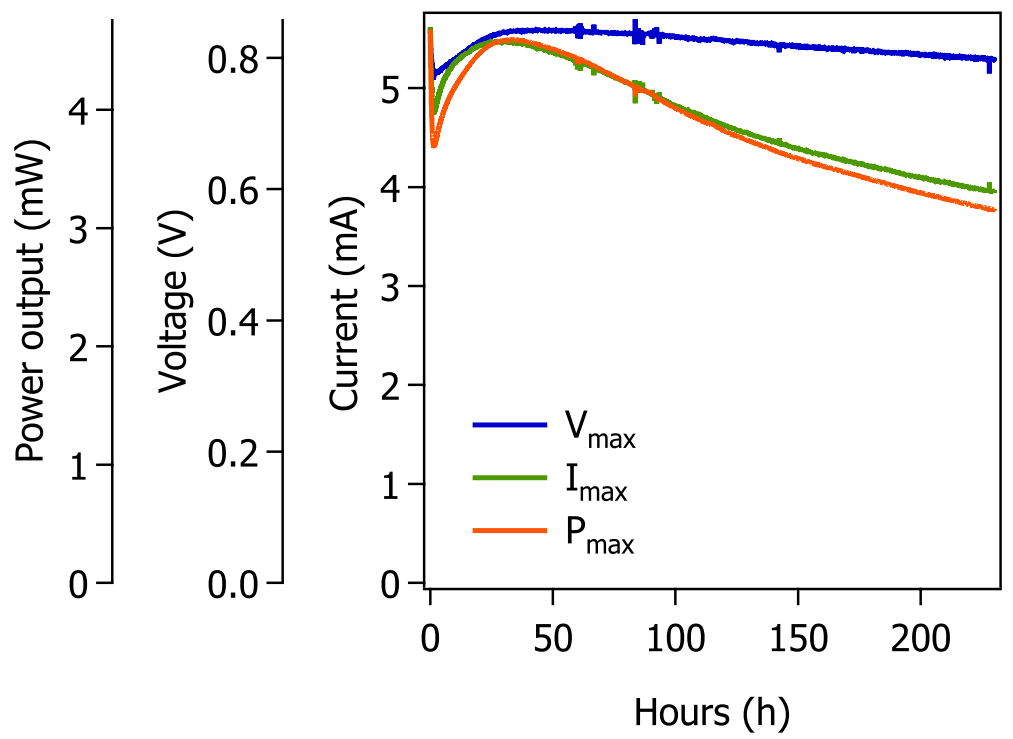

Figure SI 5: Example of the maximum power point position of a $0.25 \mathrm{~cm}^{2} \mathrm{CH}_{3} \mathrm{NH}_{3} \mathrm{PbI}_{3}$ perovskite cell sealed inside a box flushed with dry $\mathrm{N}_{2}$, under an equivalent illumination of $1000 \mathrm{~W} \mathrm{~m}^{-2}$, at $60^{\circ} \mathrm{C}$ for 230 hours.

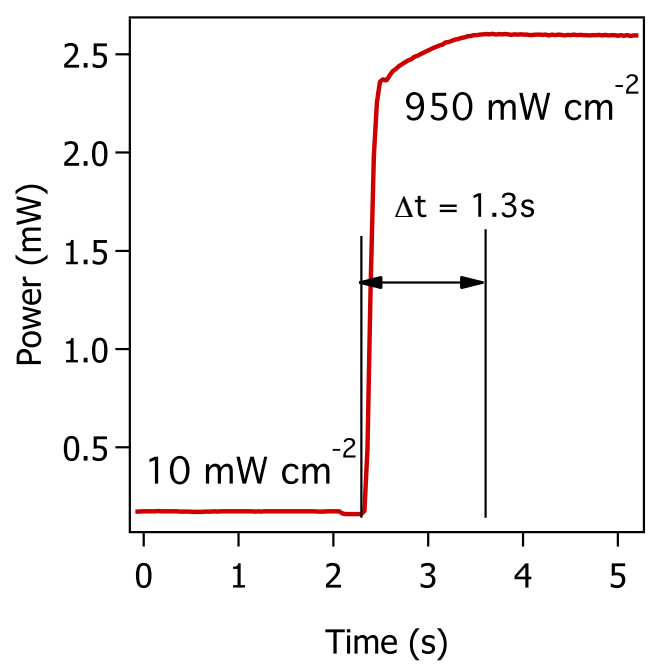

Figure SI 6: Transient response of a silicon solar cell upon a sudden change in illumination from $10 \%$ sun to about $95 \%$ sun intensity. Biasing the device at constant voltage is advantageous when the voltage at maximum power point doesn't significantly shift with changing illumination intensities. However, the voltage settling time upon changes of illumination is clearly too high for outdoor applications with rapidly changing conditions. This is due to the limited slew rate of the algorithm, but selecting faster integrated circuits and optimizing the data transfer rate can achieve higher speed. 